Article

\title{
Smart, Sustainable and Citizen Centered: A Network Analysis of Urban R\&D Trends in Seoul, South Korea
}

\author{
Bo Wang ${ }^{1,2}$, Sang Do Park ${ }^{3, *}$, Jong Youl Lee ${ }^{1}$ and Jesse W. Campbell ${ }^{1}$ \\ 1 Department of Public Administration, Incheon National University, Incheon 22012, Korea; \\ wavesue@gmail.com (B.W.); jylee@inu.ac.kr (J.Y.L.); jcampbell@inu.ac.kr (J.W.C.) \\ 2 Department of Public Administration, Guangxi University for Nationalities, Nanning 530006, China \\ 3 Department of Global Business, Konkuk University, Seoul 05029, Korea \\ * Correspondence: sdpark@konkuk.ac.kr
}

Received: 15 May 2020; Accepted: 10 July 2020; Published: 23 July 2020

check for updates

\begin{abstract}
Although it is now recognized that place matters for urban development policy, most case studies focusing on particular cities tend to adopt a high-level perspective that imperfectly captures the full spectrum of context-relevant urban development issues. This study applies semantic network analysis to a corpus of 13,852 accepted R\&D project proposals on issues related to the urban development of Seoul, South Korea. Through our analysis, we highlight important research trends and also make connections between these trends and the policy orientation and priorities of successive mayoral administrations over a period of 16 years. Although the results suggest that there is significant overlap between policy orientation and scientific research activity, the interests of research scientists cannot be reduced entirely to political priorities. The study contributes to the literature by fusing the place-based approach to urban development studies with the computational content analysis methodology. We raise several questions for future research, including questions about the relationship between policy priorities, scientific research, and academic research.
\end{abstract}

Keywords: urban development; semantic network analysis; Seoul

\section{Introduction}

Urban development planning and policy must take into consideration an increasingly sophisticated and diverse set of considerations in order to facilitate growth and provide citizens with a livable environment. For some time, a knowledge-based approach to urban planning and development centered on leveraging knowledge resources, cultures, and competencies to facilitate knowledge and information-based economic growth has gained traction [1,2]. This imperative will only strengthen as cities have begun to move beyond the information-based economies that have driven development for the past decades and into a future characterized by Forth Industrial Revolution technologies [2,3]. Moreover, new developments and projects are expected to be both eco-friendly (that is, have a low demand on the environment) and sustainable from a longer-term perspective [4]. These social, economic, and environmental goals are interdependent and evolving. The potential to realize breakthroughs is rooted in the ability to meet the ever-evolving requirements of basic realities, and it is widely believed that meaningful engagement with urban research can strengthen evidence-based decision-making, enhance professional competence and credibility, and improve the quality of evaluation $[5,6]$.

Among advanced democracies, South Korea has been a leader in using publicly funded research and development (R\&D) to pursue strategic goals [7]. Many R\&D projects aim to facilitate urban development. Although most cities in Korea are the product of a largely unplanned and rapid development wherein urban strategies have evolved over time to meet changing circumstances, other younger cities, such as the new administrative capital Sejong and Songdo International City, 
have been artificially constructed based on the specific plans of the government. The latter planned cities are designed to reflect the development of science and technology as well as livability. In such cities, the process of urban development can be regarded as a comprehensive product of converged knowledge, a key source of which is the R\&D Research Project based on open government data [8]. Seoul's development has of course been largely organic, however, due to its economic and cultural importance, the administrative and policy elite in the capital Seoul are often at the vanguard of planned urban development, and a great number of development and revitalization projects are planned and implemented in the city (a relatively recent and widely seen as successful example is that of the Cheonggyecheon revitalization project) [9]. Although national R\&D projects are announced, evaluated, and funded by the central government, due to its economic, political, and strategic importance, the Seoul Metropolitan Government actively participates in the planning stage of the proposals National Assembly Budget Office 2019. At the same time, however little is known about the content of urban development R\&D projects relevant to Seoul, and moreover there is little clarity about the extent to which they reflect the priorities of the city's administrators.

The laissez-faire, placeless approach to urban development and growth associated with the neoliberal development agenda has given way to the view that place matters, and a number of studies have focused on the knowledge-based development strategies of various globally oriented cities $[2,10]$. Such case studies facilitate urban development policy from a comparative perspective, however they do not capture the full spectrum of science-based research that is relevant to a given context. On the other hand, scholars have used bibliometric and network analysis techniques in the area of urban studies to look at a range of issues including areas of expertise and interests of faculty in the field of urban planning, urban sustainability concepts and urbanization research, urban energy systems, green infrastructure, urban climate change, urban food policy, and development participation [11-17]. Such studies bring to light how various concepts transform as well as branch off over time, with the core issues addressed by each branch of the conceptual path evolving into distinct topics [5]. These forking paths, however, relate crucially to a common origin and therefore can best be explicated through a network-style approach. At the same time, such studies fail to highlight the extent to which various concepts are relevant to a given urban context. Some scholars suggest that in many contexts, few beyond academia tend to engage with the output of academics, or, in the words of Taylor and Hurley, "Not a lot of people read the stuff." [6]

This study brings together the place-based approach of the case study with the network analysis approach used in the conceptual development studies. We explore the keywords and contents of urban R\&D in Seoul through network analysis. Specifically, through empirical analysis, we seek to understand the actual topics that are driving urban development in Seoul during salient periods of development. Until now, however, scholars have not used the network analysis approach to analyze the R\&D development trends of a single, significant place. As such, this study contributes both by shedding light on the empirical content of urban R\&D in a competitive, global city, and also highlights the methodological promise of the network analysis approach for this problem domain.

The remainder of this study is organized as follows. First, we discuss the government-funded R\&D project process, detailing the role of various actors, as well as that of the Seoul mayoral administration in the process. We describe in detail the process in which R\&D projects are formulated, evaluated, and funded. Next, we provide an overview of Korean urban development concepts, focusing specifically on the case of Seoul, which has received the most attention from urban development academics due to its economic, cultural, and political importance. Next, we introduce our research methodology and dataset, the latter of which consists of data collected from the year 2001 to 2018 . We then present the results of our analysis. We demonstrate that the network analysis approach goes far beyond the case study in detailing the empirical reality of actual research on urban development. In the final section of the study, we discuss the limitations of the analysis, but also reflect on its implications, suggesting additional research questions that can help move the discussion forward. 


\section{Research and Development for Urban Development in Korea}

Korea's rapid economic development, as well as the role of the government in this process, is well known $[18,19]$. Although the government's role in the economy has lessened greatly compared the so-called developmental period of the 1970s and 1980s, nevertheless, government continues to play a locomotive role in some areas. Recently, Korea has emerged as one of the largest per capita domestic investors on R\&D among OECD countries. From 2012 to 2017, Korea consistently ranked second behind only Israel. In 2017, about 4.29\% of GDP was spent in Korea, or about 65 billion US Dollars (According to the OECD, which uses an adjusted rather than absolute measure of spending for the sake of comparison, in 2017 Korea spent 88 billion in 2010 parity purchasing power adjusted US Dollars.) $[7,20]$. This figure consists of public, private, and foreign resources, with publicly sourced funds equaling just under $30 \%$ of total spending, or about 14 billion US dollars. These public funds are generally allocated through national research and development projects.

A national R\&D project is a government-funded, government-initiated research project that is undertaken primarily by a government-funded or private sector research institute, or a university. These projects are aimed primarily at promoting R\&D in the field of science and technology and are linked to specific national-level objectives and the need to address strategic technology goals. Leading ministries under which the R\&D projects are commissioned include the Ministry of Science and Technology, the Ministry of Defense and Business Administration, and the Ministry of Trade, Industry, and Energy.

The promotion process for R\&D proposals is managed by the National Science and Technology Advisory Council, which seeks to coordinate between the priorities of the president's office and each individual department. The Council operationalizes these priorities as well as ongoing plans related to mid to long-term national projects. Next, each central government department, referencing the framework of the Council, identifies technical issues that need to be overcome in order to meet their objectives and then reports back to the Council. Following this, the Ministry of Science and ICT reviews the national R\&D project budget proposal for each ministry and suggests any necessary adjustments. This budget is then further reviewed by the Ministry of Strategy and Finance, which is ultimately in charge of formulating the final overall R\&D budget.

Of course, the Seoul Metropolitan Government is not a central government body and therefore is not formally involved in the development of the formulation of the national R\&D planning process. However, there are several ways in which this local government body, headed by its Mayor, can have a significant influence on planning. First, as an urban center, Seoul is directly connected to the central government through the Ministry of Land, Infrastructure, and Transport, which may incorporate Seoul's local government priorities into its own R\&D proposals. Additionally, Seoul is the national capital and the center of industry, and therefore its development is in a sense a national issue. Finally, the Metropolitan Government, although not formally involved in the R\&D planning process, nevertheless actively lobbies the relevant central government organizations during the investigation and planning stages of the national R\&D budget, arguing for various tasks and priorities to be incorporated into the plan at a high level. These informal yet robust links to the R\&D policy planning system can result in the Mayor of Seoul having a significant impact on the orientation of the plan, specifically as it relates to the city [20].

Once the various needs are finalized, projects are posted on the countries National Science and Technology Information System, and interested organizations (research institutes, universities, etc.) may then submit a proposal for funding. These proposals are then evaluated by the heads of the central administrative agency. In terms of funding, research has suggested that diversification away from government research institutes began well over a decade ago [20]. Today, about $40 \%$ of projects are conducted in government-funded research institutes, with nearly $50 \%$ of projects split between private institutes and universities [20]. 


\section{Urban Change in Seoul, Korea's Capital City}

\subsection{Overview}

Seoul is the capital city of Korea and has a population of about 10 million. The 600 -year-old city has led the development of Korea as the center of its politics, economy, education, and culture. Squatters in informal settlements blocked development of the city centers after the Korean War but also represented the sign of an unmet need for urban housing. The city was developed as the state assumed responsibility for displacing informal settlements, followed by private bulldozers that cleared the land for development by the private interests that assumed title to the [21,22]. Mayors were appointed by the president until 1995 and have since been elected directly by citizens. The direct election of local mayors provided a turning point in Korean political history, leading to a vibrant local political atmosphere and functioning as a symbol of democratization. Seoul has a symbolic meaning for modern urban development and urban development policy actively reflects the results of various city-related R\&D projects. This study starts from 2002, when the conservative administration of Lee Myungbak represented the first dramatic break in Seoul urban policy, though Cho Soon and Goh Kun served before him as the first two elected mayors of Seoul.

This section describes the main features of urban thinking at the political and administrative level from 2002 until the present in order to examine how urban development has been practiced in Seoul through three periods. These three periods roughly coincide with the administration of the three administrations covered in the study. Each administration has created its own priorities for urban development that are relatively distinct between periods and have been used by the mayors to distinguish their agendas and signal their priorities to citizens.

\subsection{2-2006: Amenity}

The first conservative elected mayor of Seoul, Lee Myungbak (2002-2006), focused on development consistent with making Seoul a "livable and environmental city" in contrast to earlier development that saw "having parks as a luxury" [9,23-25]. Mayor Lee advanced the concept, which the government termed "New Developmentalism" to develop the city and overcome the legacy of unbalanced development through culture and amenity-driven economic growth $[3,26]$. Basically, Mayor Lee's administration focused on urban regeneration and culture-oriented development strategies were emphasized based on community traditions and culture, rather than physical construction, which was the dominant approach in the previous periods. Additionally, in the decade leading up to Mayor Lee's mayoral administration, Gangbuk (i.e., north of the Han River, which today divides the city) was the center of Seoul. However, with the development of Gangnam (south of the Han River), the gap between Gangbuk in the old city center and Gangnam in the new city center widened. Narrowing this gap, and avoiding further uneven development of the city, has become an important policy task.

\subsubsection{Main Aims}

As a conservative politician, Lee emphasized city competitiveness and quality of life rather than equality in his policies by enhancing urban infrastructure and promoting convenience. The main objects of Lee Myungbak were development characteristics and monitoring, balanced development and the environment, public transportation and road management, and development for popular utilization. This environmental emphasis was also a new approach in the city's administrative priorities. In general, these policies were framed as a new Korean-style urban model, emphasizing a uniquely Korean model of urban development. Even so, he continued housing development through public-private partnerships, stressed land rehabilitation, and property-led development [9,23-25].

\subsubsection{Major Actors}

Lee Myungbak (2002-2006) focused on the negative effects of rapid development and industrialization, specifically the high levels of pollution in Seoul and a lack of access to parks or, for that matter, 
any green space at all. He wanted his mayoral legacy to be a new city brand and image as a livable and environmental city. Rather than using the state to push his agenda, though, he worked in a broad "New Partnership" with private interests, including community interests, through direct negotiations as in the Cheonggyecheon restoration project [24-26].

\subsubsection{Major Projects and Performance}

Lee Myungbak started New Town projects for balanced regional development by focusing on a pro-environment policy, restored the Cheonggyecheon eco-stream, and created the Seoul Forest [24-26]. He was interested in reforming the entire public transportation system by introducing bus-only lanes and a multi-modal transportation card payment. He also paid attention to pedestrians and blocked off cars from Seoul Square. Lee's signature programs were major urban amenity developments aimed at improving the quality of urban life in Seoul, particularly for people in the crowded center [24-26]. When mayor Lee went on to become the president of Korea, he continued to emphasize a sustainable approach development, attempting to balance environmental concerns with growth [27].

\subsection{6-2011: Design}

Oh Sehoon (2006-2011) also adopted quality of life and amenity-oriented cultural policy to make the urban environment more attractive. However, he also additionally emphasized the aesthetic dimension of urban design and development $[3,9,18,26,28,29]$ Oh Sehoon put in place "Culturenomics" to advance development through urban design projects.

\subsubsection{Main Aims}

Through a new emphasis on urban landscapes, public designs, and symbolic sculptures, Mayor Oh, like Mayor Lee, also pursued urban competitiveness over equality, in his case by uniting aesthetic concerns with economic development. The main policy objects of Oh Sehoon included balanced development and the environment though he also emphasized a shift to utilization through design-oriented development, making the city creative, technological innovation, and downtown regeneration. He also continued to support traditional private housing developments, though he suspended most projects late in his term $[25,29,30]$.

\subsubsection{Major Actors}

Oh Sehoon (2006-2011) continued the cultural and environmental policy agenda of Lee's plans, though he sought future goals utilizing new technologies, and design and space considerations under the auspices of his "Seoul Tomorrow" rubric. In addition to being a global city, a networked Northeast Asian business hub, a clean healthy and green city, and a city with "culture as common and ever-present as air or water", Oh pushed for Seoul to become a world design capital [3,18,25,29]. In so doing, he expanded the scope for public-private partnerships into new areas $[9,25,29]$.

\subsubsection{Major Projects and Performance}

Mayor Oh announced the goal of making Seoul a creative cultural city in 2008 and utilized "culturenomics" to push his idea of culture-driven development. In addition to promoting cultural access, facilities, and performances, this concept included a broad view of culture that embraced historical restoration, the environment and green space, open spaces, design, and new amenities [3,18,25,29]. His vision was a city where citizens were happy and Seoul was seen as a respected cultural capital and a "global" destination. This vision would be achieved through enhancing the city's quality of life and competitiveness. Five major directions were crucial: Welfare for a more comfortable life, a dynamic economy, a trusted and transparent city administration, a clean and green environment, and an attractive cultural capital $[25,29]$. The cultural capital initiative also included a design component 
through support for fashion and design clusters, a charming urban atmosphere, promotion of a creative design culture, and the development of Seoul as a UNESCO Creative City recognized for design [25,29].

The conservative mayors' embrace of the cultural amenity model allowed them to pursue multiple development goals at a low cost and in a market-friendly way in order to address serious quality-of-life issues. They both took a hands-on approach and regularly intervened to resolve or avoid conflict, designed projects to share benefits widely, and aggressively sold residents on the benefits. However, they did not emphasize two-way communication or new media technologies.

\subsection{1 : People-Centered Regeneration}

Independent liberal Park Wonsoon became mayor in 2011. He started shifting funds to cut tuition for greater city university utilization and focused early on welfare and participation. He used participation to address the weaknesses of joint redevelopment. Mayor Park created systems to involve citizens and even had citizens vote on a new city brand slogan, I. Seoul. U. He used the technological metaphor of platform administration and worked to advance the smart city concept.

\subsubsection{Main Aims}

The new paradigm stressed preventing or reversing segregation of the lower classes. It trumpeted combining economic development with social equity. Urban regeneration was pursued through partnerships by gradual approaches instead of major projects. There was a stress placed on treating different neighborhoods differently by involving them in inclusive regeneration. This concept includes widespread consultation and provision of accessible and understandable information that is then used for monitoring by diverse groups [31]. This approach used the mayor's rhetoric of participation by embracing partnership and networking and recognized the community as indispensable in regeneration. He realized that caring for poor neighborhoods is a way of promoting equity in a way that indirectly contributes to economic growth.

Mayor Park worked to shift the development paradigm from urban renewal to urban regeneration. He also placed a priority on Seoul as a "safe city." He was concerned about the environment and brought R\&D, innovation, and balance to the focus of city planning. He tried to open the policy process to embrace participation.

\subsubsection{Major Actors}

Mayor Park was a former citizen activist interested in citizen participation in city planning. He continued this interest by opening the policy process to citizen groups and the broader public, creating new systems and platform government that took advantage of new technology and big data. $\mathrm{He}$ cancelled formerly popular redevelopment projects and reconsidered them by considering the views of the residents.

\subsubsection{Major Projects and Performance}

The main overarching project was the paradigm shift from urban renewal to urban regeneration such as in the case of Seoullo 7017, which involved negotiations with different resident groups and tried to coordinate with sellers in nearby Namdaemun Market. The goal of Seoul as a safe city was advanced, based on subway safety, and urban infrastructure renewal for safety. This included the development of walkability through safer pedestrian-only districts. Additionally, in this period, a new resident-based urban development paradigm combining the village community and social economy was proposed, and Seoul was to be developed as a global innovation city. Innovation in technology was part of the plan as Yangje was developed as an R\&D district and Hongneung as a biomedical cluster.

Mayor Park's people-centered balanced development moved forward with the 2030 Seoul Plan (20-year development plan) and the Happy 4-District Plan (balanced development in the older northeast part of the city). He pushed for open policy through deliberative policy, including the widespread and popular use of SNS and more active participation in the policy process. Specifically, Seoul implemented 
24 smart city projects to provide customized spatial service based on citizen needs, employed two-way citizen participation through SNS, and pushed for smart decision-making based on data in the four major fields of transportation, welfare, economics, and administration.

To summarize the three periods, the characteristics of different phases in the history of urban regeneration in Seoul are listed in the table below. In broad strokes, it can be seen that the values driving urban development thinking have diversified, with an almost exclusive emphasis on economic growth giving way to a more complex set of value-based considerations, while also including a more diverse set of actors in policy decisions. This Seoul-level evolutions to some extent mirrors the evolution of issues and actors at the national level [27]. We summarize these changes in Table 1.

Table 1. Summary of urban development paradigms in Seoul.

\begin{tabular}{|c|c|c|c|}
\hline Phase & Major Aims & Major Actors & Major Performance \\
\hline Before 2000 & $\begin{array}{l}\text {-Clearance } \\
\text {-Physical redevelopment }\end{array}$ & -State & -Physical improvement \\
\hline 2002-2006 & $\begin{array}{l}\text {-Less emphasis on 'bulldozing' and } \\
\text { comprehensive redevelopment. } \\
\text {-Balanced development (remedying } \\
\text { "divided city") }\end{array}$ & $\begin{array}{l}\text {-Public-private partnership } \\
\text {-intersectoral partnerships } \\
\text { ("New partnership": state, } \\
\text { private sector and community) }\end{array}$ & $\begin{array}{l}\text {-Amenity-environmental concerns of local } \\
\text { residents } \\
\text {-Large scale flagship projects such as Seoul } \\
\text { Forest, a reworked traffic system, stream } \\
\text { restoration, and parks } \\
\text {-Overall benefits would eventually go to all } \\
\text { groups through better environment and } \\
\text { improved economy }\end{array}$ \\
\hline 2006-2011 & $\begin{array}{l}\text {-Emphasis on rehabilitation } \\
\text {-Property-led urban regeneration }\end{array}$ & $\begin{array}{l}\text {-Public-private partnership } \\
\text {-intersectoral partnerships } \\
\text { ("New partnership": state, } \\
\text { private sector and community) }\end{array}$ & $\begin{array}{l}\text {-Emphasis on cultural and environmental } \\
\text { concerns of citizens } \\
\text {-Large scale, consumption-oriented projects } \\
\text { such as shopping malls, convention centers, } \\
\text { atrium hotels, etc. } \\
\text {-Disadvantaged groups and neighborhoods } \\
\text { would eventually share in the wealth } \\
\text { generated through the trickling down effects }\end{array}$ \\
\hline 2011-Present ${ }^{1}$ & $\begin{array}{l}\text {-Preservation and improvement } \\
\text {-Balance between sustainable } \\
\text { simultaneous economic, physical } \\
\text { and human regeneration } \\
\text {-Balance between economic, } \\
\text { physical, and human renewal } \\
\text {-Partnership and networking: } \\
\text { community becomes a full partner } \\
\text { in regeneration. Enhanced care for } \\
\text { poor neighborhoods and promotion } \\
\text { of equity which indirectly } \\
\text { contributes to economic growth }\end{array}$ & $\begin{array}{l}\text {-"Bring the Community Back in" } \\
\text {-“Community First" }\end{array}$ & $\begin{array}{l}\text {-Seoullo } 7017 \\
\text {-Use of SNS to connect to citizens } \\
\text {-Happy 4-District Plan }\end{array}$ \\
\hline
\end{tabular}

${ }^{1}$ The periods do not perfectly match the data, which follow a regular schedule. However, Mayor Park took over near the end of 2011 following the election triggered by Mayor Oh's resignation. It was not possible to split the 2011 data between the two administrations so the Park administration is represented by the 2012-2018 data.

\section{Research Design and Methodology}

\subsection{Research Questions}

This study aims to identify the main research trends approved in R\&D projects in a major city and compare them to the major development trends over time. South Korea was selected as being outside of the European Union and United States focus that has dominated much of the planning research. Seoul was selected because of its important relationship among Korean cities and role in setting the priorities and trends in other cities through its size, influence, and its relative independence [32]. The time period was selected due to the data available that would match a succession of the entire administrations in order to examine the relationship between development and research trends over time. Specifically, this study examines and matches the keywords and contents of Seoul urban development and R\&D in order to determine the central ideas and core issues related to Seoul development during the period. This process lays the foundation for understanding how these core issues and their evolution can point the way to emerging future directions for R\&D and urban development in Seoul. 


\subsection{Data}

Unstructured data used in this study were obtained from the National Science \& Technology Information Service (NTIS). This open-source platform shares information related to national R\&D projects and science and technology, which, as explained above, are managed by central government departments, and integrates related information so that the results can be used socially. We selected "Urban R\&D" as the subject words and extracted 13,852 related R\&D documents from 2002 to 2018. Next, according to the terms of the mayors of Seoul, the data was merged/arranged into three periods (1st period: 2002-2006, second period: 2007-2011, third period: 2012-2018). Next, data cleaning was performed by extracting the unstructured data (R\&D titles, keywords, and abstracts) included in the documents, and the words for analysis were extracted by time.

\subsection{Text Mining}

The term frequency-inverse document frequency (TF-IDF) technique was used to address the limitations of analyzing the importance of words based on frequency alone. TF-IDF values are based on both the frequency of a word in a particular document and the number of documents that contain the word. According to Salton and Buckley (1988), this metric can be used to filter out common words and captures the importance of certain words. We use the classical TF-IDF formula as represented in the following equation:

$$
\mathrm{TF}-\mathrm{IDF}=\mathrm{TF} \times \mathrm{IDF}=\mathrm{tf}_{x, y} \times \log \left(\frac{\mathrm{N}}{\mathrm{df}_{x}}\right)
$$

In the equation, $t f_{x, y}$ denotes the frequency of term $\mathrm{x}$ in document $\mathrm{y}, d f_{x}$ denotes the number of documents containing $\mathrm{x}$, and $\mathrm{N}$ indicates the total number of documents.

In general, centrality captures the degree to which a particular node is centered in a network. The node is a corpus of the keyword. The link is the correlation between the co-occurring frequency of the groups. Depending on the features of the relationship, centrality can be interpreted in various ways, including degree, closeness, and betweenness (Borgatti, Everett, \& Freeman, 2002; Zhang et al., 2011). [33,34] In the present study, the degree of centrality is measured by quantifying the degree to which a node is centered and also by the strength of its relationship to other nodes. In this case, centrality is expressed as follows: [35]

$$
C_{D}^{\prime}\left(N_{i}\right)=\frac{C_{D}\left(N_{i}\right)}{g-1}
$$

where $C_{D}^{\prime}\left(N_{i}\right)$ denotes node $i$ 's degree of centrality, in which the value of $C_{D}\left(N_{i}\right)$ is dependent on the size of the network. $C_{D}\left(N_{i}\right)$ here denotes the degree of centrality of node $i$, calculated by $\sum_{j=1}^{g} x_{i j}, i \neq j$. $\sum_{j=1}^{g} x_{i j}$ in this equation is the number of connections that node $i$ has with other nodes, $g$ is the total number of nodes, and $x_{i j}$ specifies whether there is a connection between node $i$ and other nodes. $g-1:: x_{i j}=1$ when there is a connection; otherwise, $x_{i j}=0$.

\subsection{Semantic Network Analysis}

Semantic network analysis extracts words with meaning (concepts) from language messages (texts), selects key keywords, and constructs a network based on the semantic connection between them. This is a methodology to analyze the structural characteristics of language messages by using various analysis indicators of the visualized network. The biggest advantage of applying network analysis is that the spatial representation of the language structure allows us to visually grasp the relationship between the main concepts presented in the text (as derived from a particular term) and other concepts (deriving from other terms). In addition, by finding the concept of high network centrality, it is possible to understand the intention and meaning of the whole text. Therefore, this methodology is useful for formalizing unstructured data that is difficult to quantify when conducting empirical research. Therefore, in order to analyze textual data such as R\&D title, keywords, and abstracts structurally 
and by time period, the authors selected the network analysis methodology as the most appropriate methodology, and the overall analysis process is presented in Figure 1.
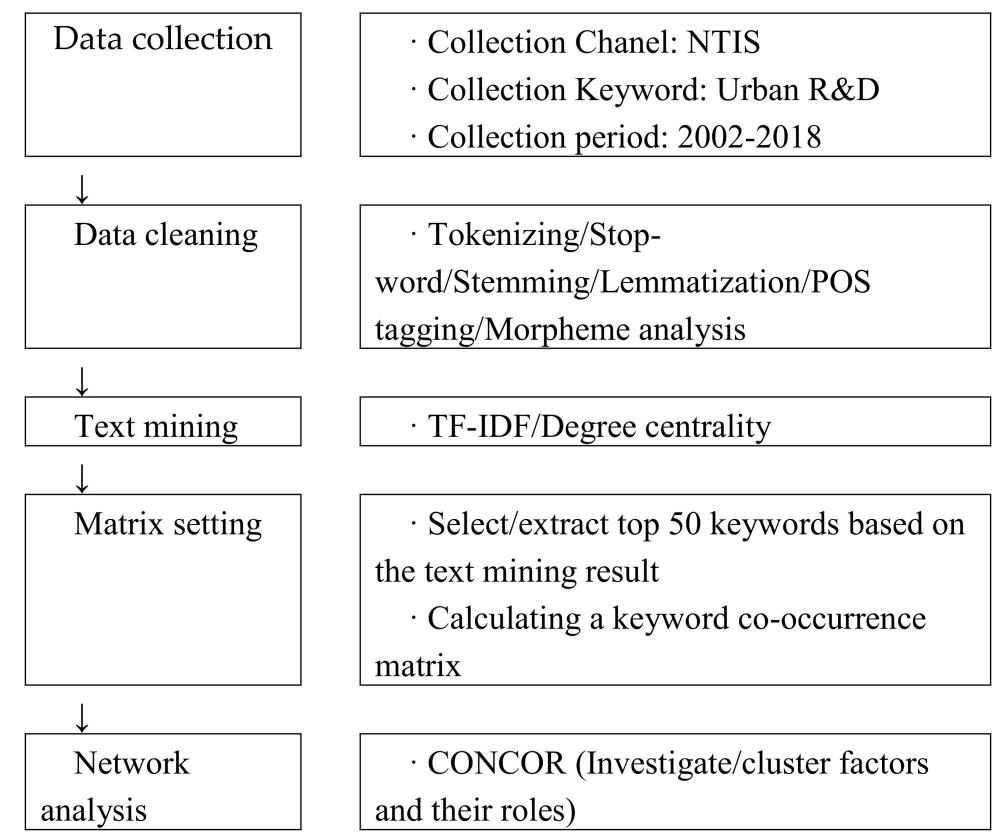

Figure 1. The framework of network analysis process.

Semantic network treats a word as a node in a network and determines whether there is a co-occurrence between certain words (co-occurrence is the links among nodes which are to be considered in calculating closeness) [36,37]. CONCOR analysis is a representative methodology of the semantic network analysis approach. CONCOR analysis primarily analyzes the correlation metrics of words derived from text mining and presents information about network type, density, hub node, and cluster group. CONCOR analysis can be used to group factors/issues (deriving from terms) with similar positions and to describe the relationships between the groups [38]. The CONCOR method groups the nodes according to the method of constructing groups in the semantic network. The equation for constructing the correlation matrix used in this analysis is expressed as follows: [39]

$$
r_{i j}=\frac{\sum_{p=1}^{2 R} \sum_{k=1}^{g}\left(x_{i k p}-\overline{x_{i .}}\right)\left(x_{j k p}-\overline{x_{j}}\right)}{\sqrt{\sum_{p=1}^{2 R} \sum_{k=1}^{g}\left(x_{i k p}-\overline{x_{i .}}\right)^{2}} \sqrt{\sum_{p=1}^{2 R} \sum_{k=1}^{g}\left(x_{j k p}-\overline{x_{k}}\right)^{2}}}, i \neq j \neq k
$$

where $r_{i j}, R, g$, and $x_{. . r}$ represent, respectively, the correlation coefficient between factors $i$ and $j$, the number of relationship types, the number of nodes, and the relationship strength in relation type $r$. TF-IDF runs from 0 to 1 , with 0 capturing high frequency (and therefore low relevance) and 1, low frequency (and therefore high relevance). Closeness ranges between 0 and 1, with 0 representing no relationship and 1 representing relationships with all other noted. $r_{\mathrm{ij}}$ is the Pearson correlation coefficient. Based on equations 1 through 3, we generate a semantic network that indicates similar relations in the text. Keywords with high levels of closeness are grouped, which we interpret to mean an important knowledge cluster for urban development in Seoul. Through this approach, we aim to address our main research question: What are the key and influential research themes that are related to urban development in Seoul? 


\section{Results}

\subsection{The Results of Text Mining: TF-IDF and Degree Centrality}

After refining the text data collected for this study, TF-IDF and centrality were measured, and text mining results were derived for the top 50 words that have a relatively strong influence on the network. Table 2 compares and analyzes the ranking of the TF-IDF and centrality values of the words. In particular, we present the words with the latter rank relatively higher than the former. This means that it is more central than the frequency of word exposures, meaning that it is connected to many nodes in the network. In other words, although the frequency of exposure may be low, it can be interpreted as a keyword that plays a relatively important role in the network.

Table 2. The results of text mining by each period.

\begin{tabular}{|c|c|c|}
\hline \multicolumn{2}{|c|}{ Subject Words } & Network Marketing \\
\hline \multicolumn{2}{|c|}{ Significant Words } & Words(1)/(2) \\
\hline \multirow{3}{*}{ Period } & 2002-2006 & $\begin{array}{l}\text { Korean-style model (10/6), Local community (13/10), Urban } \\
\text { management (14/9), City planning (18/14), Culture (20/16), Information } \\
\text { (22/19), Efficiency (27/24), Industry (28/25), Education (32/27), } \\
\text { Functionality (39/35), Recycling (40/30), Real-time(41/29), Economy } \\
\text { (43/31), Control (44/36), Improvement (46/40) }\end{array}$ \\
\hline & 2007-2011 & $\begin{array}{l}\text { Social integration (20/14), Intelligent (21/18), Monitoring (24/19), } \\
\text { High-efficiency (31/27), Technology convergence (36/33), Image (37/33), } \\
\text { Education (38/44), Strategy (40/37), Recycling (44/40), Hybrid (45/39), } \\
\text { Policy (46/41), Landscape (49/42) }\end{array}$ \\
\hline & 2012-2018 & $\begin{array}{l}\text { Utilization (6/3), Social integration (10/7), Urban reform }(14 / 11) \text {, } \\
\text { Technology convergence (24/20), Real-time (40/27), Safety }(43 / 26) \text {, } \\
\text { Automation (44/36), Community (47/33), Life (48/37), Mobile (49/45), } \\
\text { AI Artificial intelligence (50/32) }\end{array}$ \\
\hline
\end{tabular}

Note: (1) and (2) refer to TF-IDF rankings and degree of centrality, respectively. The results were presented by selecting only the words with a rank of (2) higher than three levels higher than the rank of (1) (For example, in the period of 2002 to 2006, the keyword "Korean style model" has a TF-IDF rank of 10 (11) and the degree of centrality (2)) has a rank of 6 . Therefore, the difference between the TF-IDF and the degree of centrality is 4 , which is greater than 3 . When we generate the semantic network we use the TF-IDF to get the node and we connect the node by connection value rij. Low closeness means the low number of connection among keywords. However, a high TF-IDF signifies the importance of keywords even if the keyword appears infrequently in the text.).

First, we collected the keywords related to the research topic and determined their TF-IDF values and degree of centrality. Based on the power-law distribution, a characteristic of big data, upper words that influenced the research topic were used. From NTIS database, approximately 43,778 keywords were collected, after which 3390 word combinations (first period: 779; second period: 1126; third period: 1465) were obtained after data cleaning. After text mining, the top 50 TF-IDF values were selected for analysis. (We confirmed that the words with TF-IDF rankings of over 50 were not significantly correlated with cultural exchange. We also empirically confirmed that the number of appropriate words in the visualization process was 50-120 [40,41]. Therefore, the threshold of 50 words was deemed important for analyzing the level of cultural exchange between the two countries (see Table 2).

First of all, looking at the early keywords relating to urban R\&D in the first period, Korean-style model, urban management, city planning, culture, efficiency, functionality, control, and improvement demand attention. The development of Korean cities in this period can be seen as securing the unique urban development identity of Korea and promoting the development that is appropriate for Korea's cultural/emotional/geographic space. In particular, industry and economy are still emerging as important keywords for urban development at this time, which means that urban development is still proceeding based on economic growth models (August 2016). Also, the two words "recycling" and "real-time" rank higher in degree centrality than in TF-IDF. This means that in the discourse of reality, the occurrence of the two words is not high, but they are recognized as important words for researchers. 
Looking at the key keywords in the mid-term, we should pay attention to words such as intelligent, monitoring, high efficiency, technology convergence, and hybrid. This period can be seen as an urban R\&D focused on high-technology projects. In particular, the advent of the Fourth Industrial Revolution, the emergence of ICT technology, and the convergence of the Internet platform and human life mean that it has emerged as an important consideration for urban development.

In recent urban R\&D, we should pay attention to technology and people. Urban technologies are being activated on a user basis, with words such as mobile, automation, technology convergence, and artificial intelligence (AI). In particular, research is being conducted to utilize AI that can change the management of cities in an integrated manner and allow meticulous technical judgment. On the other hand, it is also possible to see the trend of balanced development of urban planning and technology centering on "people". It is undeniable that our urban life has been facilitated by the development of technology, but some words (e.g., life, community, safety, etc.) suggest that human-oriented urban development/city management research prevents human life from being buried in technology. It is necessary for the sustainable development of the city.

\subsection{The Result of Network Analysis: CONCOR}

After text mining, a semantic network analysis using the matrix of the top 50 words was conducted. Through this process, it was possible to investigate the structure of the semantic network and the matrix clusters. (CONCOR analysis method is used to measure the distance between two keywords using Cij and finds a dendrogram by connecting close ones and then find groups by cutting the dendrogram at the appropriate level. The keywords that belong to same group have a similar correlation and form a homogeneous group. The reason for this is to extract keyword groups with similarity from the semantic network.) Table 3 displays the results of the CONCOR analysis.

Table 3. The results of the CONCOR analysis.

\begin{tabular}{cccc}
\hline Subject Words & \multicolumn{3}{c}{ Urban R\&D } \\
\hline Collecting Channel & $2002-2006$ & NTIS & 2012-2018 \\
\hline Period & 6 & $2007-2011$ & 5 \\
\hline Number of major clusters & 11.240 & 5 & 30.640 \\
\hline Average degree & 0.911 & 19.633 & 4.605 \\
\hline Average clustering coefficient & Utilization (137.115), & 2.192 & System (58.512), \\
Major hub nodes (betweenness & $\begin{array}{c}\text { Environment (105.093), } \\
\text { Characteristic (50.327), } \\
\text { Kontrality }>\text { 50) } \\
\text { Mon-style model (50.560), } \\
\text { Road Management (74.803) }\end{array}$ & $\begin{array}{c}\text { Utilization (62.624), } \\
\text { Environment (57.961) }\end{array}$ & $\begin{array}{c}\text { Technology (56.682), } \\
\text { Utilization (51.896), } \\
\text { Smart (51.341) }\end{array}$ \\
\hline $\begin{array}{c}\text { Significant keywords in the } \\
\text { major clusters }\end{array}$ & $\begin{array}{c}\text { Brand, Utilization, } \\
\text { Environment, Image }\end{array}$ & $\begin{array}{c}\text { Technology, Network, } \\
\text { Design, Space }\end{array}$ & $\begin{array}{c}\text { System, Technology, } \\
\text { Bigdata, Platform }\end{array}$ \\
\hline
\end{tabular}

In the first period, six major clusters were found. The average degree (11.24) denotes the average value of the sum of the in-degree and out-degree of the nodes and serves as a measure for determining the connectivity between certain words. The average clustering coefficient was 0.911 , a figure that implies a closeness with neighboring nodes. In the entire network, six hub nodes were found: Utilization, environment, Characteristic, Korean-style model, Monitoring, and road management, of which four (brand, utilization, environment, and image) are in key positions in the clusters. The clustering analysis showed that words related to urban development issues (design, industry, integration, brand, etc.) formed a cluster. Words from urban-development-related technologies (technology, sensors, data, control, information, etc.) formed another large cluster. In addition, words related to the problems of the urban development process (air pollution, energy, groundwater, waste, etc.) are grouped together, and the words for the improvement of the urban environment (recycling, environment, water quality management, etc.) 
are also grouped together. Urban research at this time was mainly the study of collective intelligence to solve various issues related to urban expansion/development/renewal. It should be noted that during this period, we began to study the unique model of urban development that applied the Korean model, and the early stages of establishing urban image and identity reflecting Korean culture were carried out (see Figure 2).

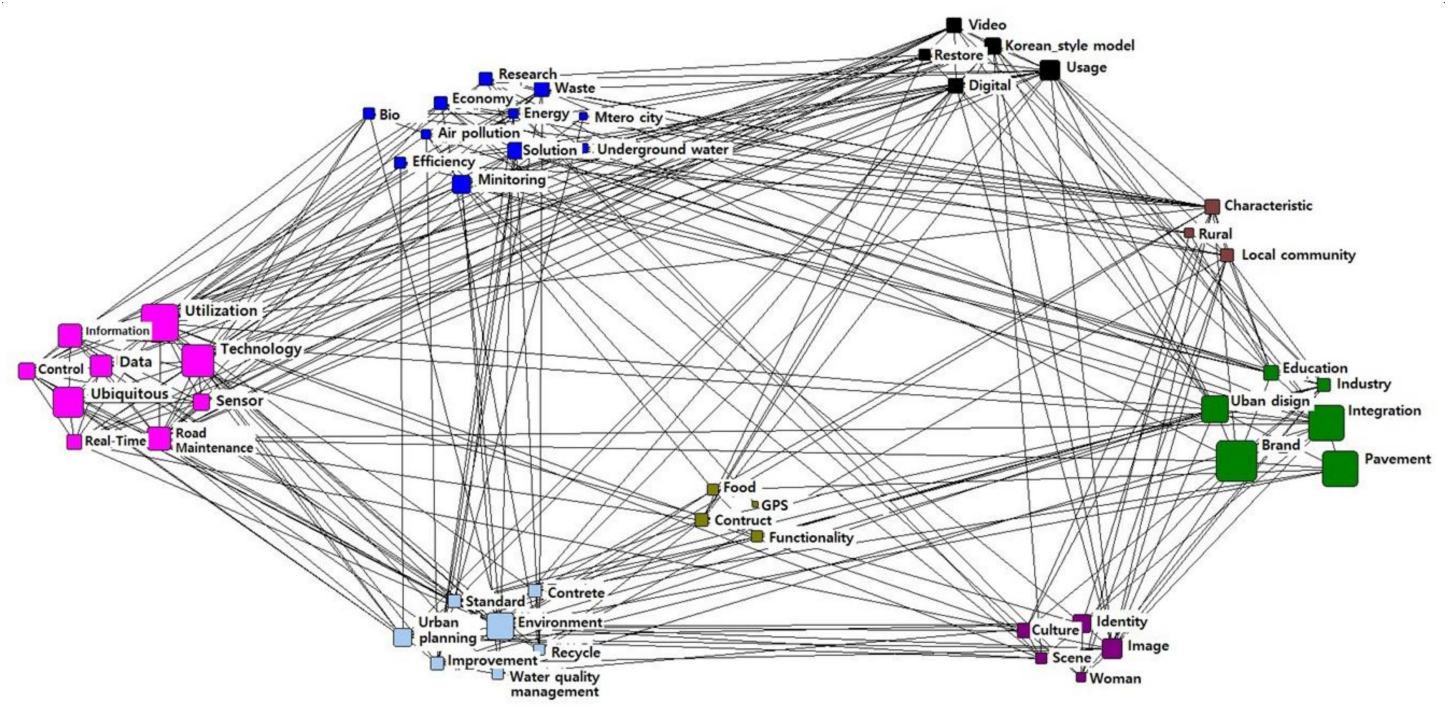

Figure 2. The result of CONCOR by period 2002-2006.

In the second period (see Figure 3), a total of five major clusters were identified. Average degrees (19.633) and average clustering coefficients (2.192) rose significantly over the previous period. This means that the various themes of urban development research at this period are more closely integrated and related. First, we can see that the word "technology" forms a clustering with words such as energy, low carbon, environment, eco-friendly, and high efficiency. This suggests that if the technology of the previous period was related to managing/controlling the city in real-time and producing/collecting information, the technology of this period was deeply related to the "environment" problem related to the life and sustainable development of the urban population. In particular, this period was a time when environmental issues for fine dust were raised strongly, and energy efficiency improvement and energy-saving technology (hybrid) were rapidly developed. Another feature is that the words related to smart, wireless, network, platform, and sensors form a cluster, and the urban studies are in contact with the flow of the Fourth Industrial Revolution. These urban-related intelligent (ICT, IoT) technologies and research flows have been found to have organic relationships in combination with various issues of the city (climate, prediction, design, integration, space, convergence, etc.).

In the third period (see Figure 4), five major clusters were found, with an average degree of 30.640 and an average clustering coefficient of 4.605. The overall network structure of this period can be seen to have a much stronger relationship between nodes (words) than the two previous periods. "Technology" here is much more coupled with urban life and future-oriented words than with clustering in the past. For example, they combine with words such as convergence, integration, optimization prediction, 3D, and smart to form a cluster. This suggests that recent urban technology research is concentrated in the fields related to future prediction, disaster prevention, urban safety, and urban social integration. This is an important research subject for developing cities in the past in terms of hardware, but now it is more focused on sustainable development through city integration, safety, and prediction. Another feature is the smart trend of urban-related research driven by the rapid development of IT technology. Artificial intelligence, big data, etc., have become important keywords in urban research, and intelligent, standard, automatic, and information related to them have a relatively strong relationship. Finally, we should note that urban research extends not only to technical fields. but also to region-based 
communities. In other words, research on the humanities related to the lives of the residents also attracted attention as an important field for maintaining and developing the city. Because advances in technology can lead to human alienation, and bleak urban development and renewal can accelerate this exclusion of humans. Therefore, not only developing the city, but also enjoying life in the city and conducting research on the lives and communities of the residents who live in everyday life can be said to be the work that paints the achromatic color of the city as human.

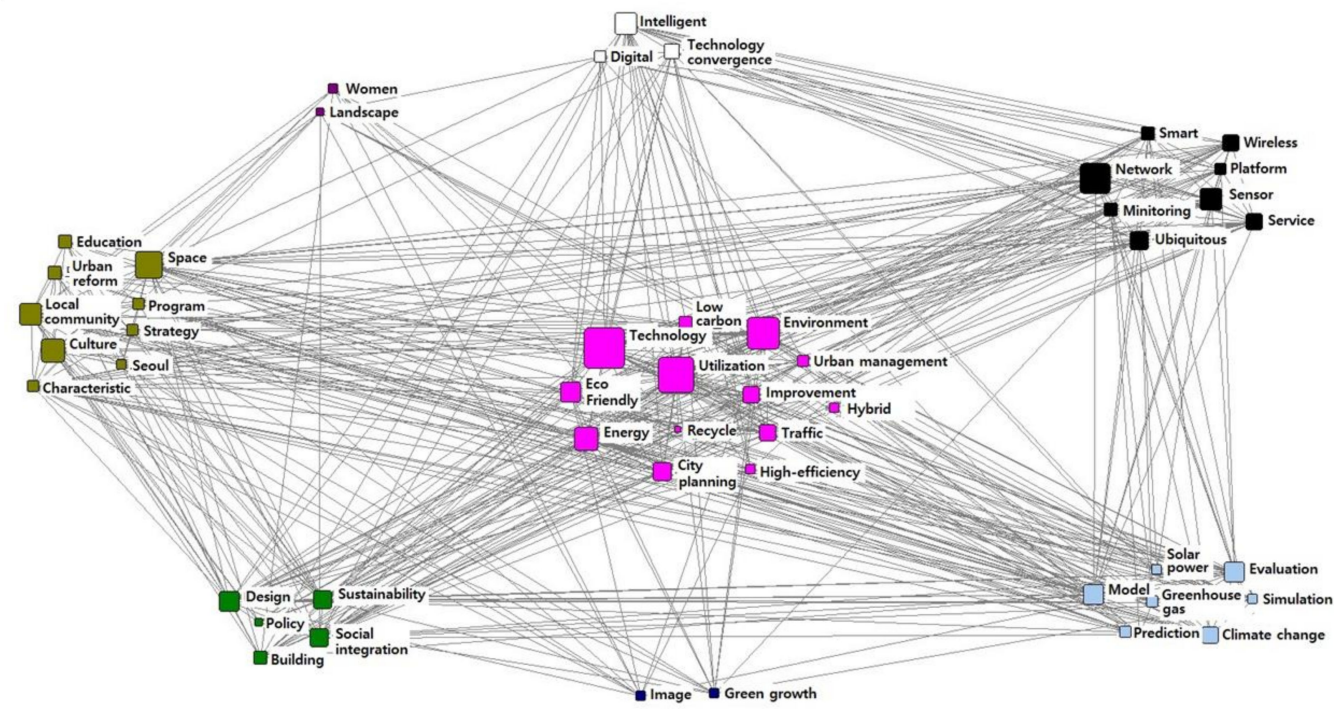

Figure 3. The result of CONCOR by period 2007-2011.

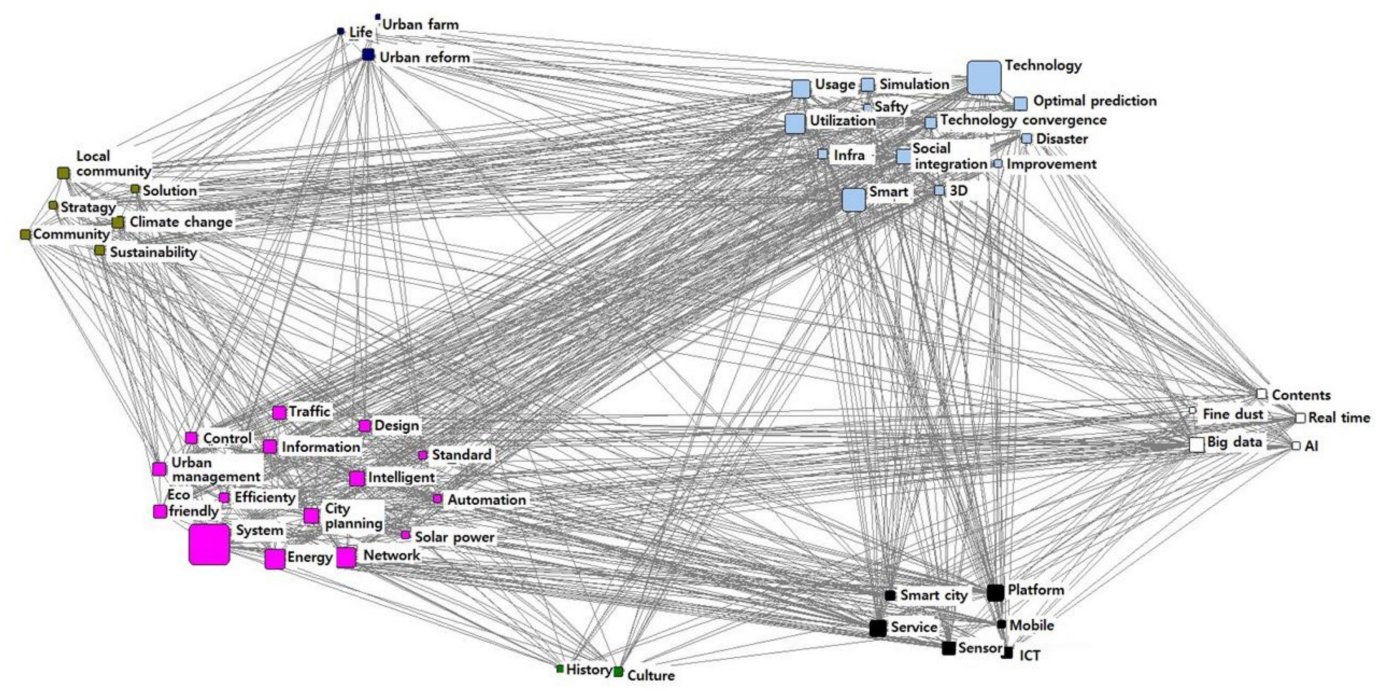

Figure 4. The result of CONCOR by period 2012-2018.

\section{Discussion and Conclusions}

This study used semantic network analysis to examine urban development trends in Seoul, South Korea. Through an analysis of data gathered from the National Science \& Technology Information Service (NTIS), the main trends of urban development research were identified. Key words in urban development research were revealed and related to corresponding urban developments, using Seoul to represent Korean trends. Although the topics focused on by scientists do, to an extent, reflect the policy priorities of mayoral administrations, we found a greater diversity of research topics that were beyond the scope of city urban development policy. 
This study makes several contributions to the literature. First, this study identified the issues and interests related to urban development research, based on word importance and the degree of centrality. In the NTIS, smart city and technology-related words for urban development research appeared the most. However, the trend of urban development performance showed that environmentally related sustainability continues through the different time periods [5].

Second, the semantic network analysis shows that the primary major hub nodes of urban development research have shifted from a focus on hardware to software. In the past, construction and monitoring were major hub nodes. These central ideas, however, have been replaced by smart and technology in recent years. This trend is consistent with the realities of urban development in Seoul. Recently, Seoul focuses on urban regeneration using the concept "smart" [42].

These trends parallel trends in Seoul. Utilization, environment, monitoring, and road management correspond to the enduring prominence of the bulldozer, which is symbolic of redevelopment, improved amenities, and livability in Seoul, and the major reworking of Seoul's transportation system under Mayor Lee $[9,20,24]$. Technology, network, design, and space emerge under Mayor Oh, following his emphasis on design (Im et al. 2014; Lee \& Hwang 2012; Lee and Anderson, 2013a; Hwang 2014) [9,18,26,29]. Technology, systems, big data, and platforms emerge along with smart following Mayor Park's "platform administration," representing a vision of smart participation $[17,43,44]$. The three periods may thus symbolize the transition from redevelopment to regeneration to smart sustainability [24,42,45].

The earlier model prior to the period of this study had been one of development at all costs, with little attention paid to livability, environment, or even resident needs [46]. During the period of this study, however, the focus on redevelopment receded, with a clear central focus on environment emerging, representing concerns about sustainability, as well as climate change, and construction of an urban green infrastructure $[5,14,15]$. The intermediate attention to amenity, exemplified by branding and design, represented a transitory period associated with addressing problems of gentrification and decline through regeneration methods $[9,24,28]$. The final period saw the culmination of technology and smart methods to address people-oriented problems of development [42].

Practical utilization appears to be a trend flowing through all three periods, while an emphasis on the environment receded by the third period with technology rising in the second period and continuing into the third, and smart emerging as a new topic in the final period. We can see a definite shift in emphasis over the 16 years, but the shift was more gradual in the network and semantic analysis than the divisive politics of the period may have suggested. The changes in research nodes and cluster keywords appear to represent shifting methods for dealing with Korean urban development. Indeed, the mast dramatic shift occurred between the first two conservative periods, where the brand, utilization, environment, and image keywords gave way to technology, network, design, and space, and six major hub nodes gave way to three in the second period. In terms of $R \& D$, then, the $O h$ administration represented a greater shift from the one before it than did the Park administration. The latter two periods shared two major hubs, while the keyword technology in the second period presaged an increase in technology-oriented keywords in the final period. Further, the reduction of hubs and the increase in clustering coefficient support the notion of a consolidation of more cohesive $R \& D$ concerns over time.

The disappearance of environment from the third period goes against the rise of climate change and environmental sustainability as urban issues internationally $[5,15]$. However, this may represent less a lack of interest in environmental concerns rather than a shift of the environment from an explicit quality of life issue under the conservative mayors to an issue to be addressed under more general participatory data, systems, and technology approaches under Mayor Park. The environment may be seen as something that now falls under smart, systems, big data, and technology research platforms [42].

This study sheds light on major trends in urban development research and practice Seoul city over the past two decades. Using semantic network analysis, we were able to show have priorities have transformed over time, and secondly were able to show how these transformations mirrored to an extent changes in policy orientation at the mayoral level. In general, our analysis demonstrates that 
the priorities of mayoral administrations in Seoul have shifted to include more diverse values and goals, a process that links up to similar processes at the national level $[27,47]$. While we think that these contributions are non-trivial, nevertheless, this study has limitations, which we note here. First, the time period of information gathered from the NTIS in Korea was limited, starting in 2002. Therefore, the trend before that year was not explored. This is a limitation coming from data availability. Second, this study only identified research projects funded by government agencies. Therefore, future research should expand their research scope including the nongovernmental sector. Third, while we can clearly see how trends in research co-develop with administrative priorities, our study does not show which way causality runs between the world of research and policy. Additionally, our analysis, although based on best practices and reasonable choices, we feel, nevertheless would produce slightly different results if the parameters of the mathematical framework were altered. Consequently, we cannot be certain that our network analysis perfectly reflects the phenomenon as it has actually occurred. However, this is a limitation common to all research of this type.

The main contribution of this study is the fusion of the place-based approach with the quantitative approach. Various cases studies on major cities have been a central component of the urban development literature, however, a purely qualitative document or interview-based analysis of development trends in a given city, especially one of a significant size and with a significant research budget, will invariably give only a fragmented view of the full development of urban development thinking. Our study attempts to look at higher level policy directions—which undoubtedly have a political dimension —with actual R\&D trends over a given period. Unsurprisingly, policy directions are relatively simple compared with the full range of topics being researched by the research institutes and scientists, however, we at the same time found a number of parallels. Although there is no way for us to demonstrate causality between policy dialogue and the research agendas of scholars, nevertheless, it seems fair to say that policy dialogue in Seoul does to an extent shape the direction of empirical urban research, which is not necessarily a surprise given the manner in which the document corpus we examined came into being.

There are a number of questions for future studies that can extend our work here. First, although we try to demonstrate a degree of correspondence between policy dialogue and urban research, in some ways, our results suggest only that political and policy priorities come in Seoul to be reflected (as a component) in the research agendas of scientists. However, an additional question might look at the relationship between $R \& D$ projects and more academically oriented scholarship. A cursory search on Web of Science suggests that, in the fields of Regional and Urban Planning and Urban Studies alone, between 2005 and 2020 over 200 studies that mention Seoul were published in English in Social Science Citation Indexed journals. Of course, over this same period, there are many more studies on Seoul published in the Korean language. We may hypothesize that scholars, even though they are often funded by grants from the Korean government, may have an agenda that is less amenable to political or practitioner priorities than scientists specifically funded for government projects. This would be in line with much research on the relationship between scholarship and practitioner concerns $[6,48]$ (On the other hand, see Hasanagas, who suggests that many practitioners are sufficiently autonomous and skilled that they have little use for academics, even in matters related to scientific issues) [49].

However, this research has been done predominantly in the West, and therefore, given the somewhat more symbiotic relationship between academia and government that is characteristic of the Korean context, it would be interesting to see whether this research can be generalized.

A second potentially interesting area of study relates to the relationship between urban development research and implementation. Although we can see a certain correlation between the political and policy priorities of the local administrations of the city of Seoul and the direction of urban development scientists, we can also see that much of the research themes explored by the latter tend to go significantly beyond the priorities of the practitioners. Again, even though these are research projects that are driven by policy priorities, the implementation of policy priorities of course will be constrained by what is possible. However, looking into this question would require the 
generation of a second dataset focused on actual implementation rather than the high-level overview of policy priorities that we have described in this study.

A third potentially interesting avenue for future research relates to the relationship between the R\&D trends in soul and those of some other globally competitive cities, specifically those situated in the West, where the bulk of research has already been done. Of course, like our first two questions for future research, exploring this question in any detail would require the generation of a dataset of similar richness such that a comparison could be done. Such a study, we think, would also represent a methodological contribution to the literature.

This study examined the keywords of Seoul publicly funded urban R\&D and broadly matched them to the urban development trends under the three mayoral administrations covered in the study. These were found to represent the central ideas and core issues related to Seoul development (and by extension Korean urban development) during the period 2002-2018. It is expected that future funded research will similarly match trends in urban policy and development in Seoul and that research topics will evolve to represent changing concerns rather than change dramatically even with partisan changes in the city. A trend in favor of technology will continue, along with smart methods and big data. However, the increasing salience of environmental sustainability and climate change as major issues suggests that these may emerge as separate topics in the near future, though they currently appear to be addressed under research into smart technologies and other areas.

Author Contributions: Supervision, B.W.; Formal analysis, S.D.P.; Writing-Original draft, J.Y.L. and J.W.C. All authors have read and agreed to the published version of the manuscript.

Funding: This study was supported by a 2016 Incheon National University post-doctoral program grant.

Conflicts of Interest: The authors declare no conflict of interest.

\section{References}

1. Knight, R.V. Knowledge-based Development: Policy and Planning Implications for Cities. Urban Stud. 1995, 32, 225-260. [CrossRef]

2. Yigitcanlar, T.; Fachinelli, C. (Eds.) Knowledge-based urban development redefined: From theory to practice knowledge-based development of cities. In Summit Proceedings of the 4th Knowledge Cities World Summit; The World Capital Institute and Ibero-American Community for Knowledge Systems: Rio de Janeiro, Brazil, 2011; pp. 389-399.

3. Hartley, K. Cultural policy and collaboration in Seoul's Mullae art district. Geoforum 2018, 97, $177-188$. [CrossRef]

4. Tae, S.; Shin, S. Current work and future trends for sustainable buildings in South Korea. Renew. Sustain. Energy Rev. 2009, 13, 1910-1921. [CrossRef]

5. Fu, Y.; Zhang, X. Trajectory of urban sustainability concepts: A 35-year bibliometric analysis. Cities 2017, 60, 113-123. [CrossRef]

6. Taylor, E.J.; Hurley, J. Not a Lot of People Read the Stuff. Australian Urban Research in Planning Practice. Urban Policy Res. 2016, 34, 116-131. [CrossRef]

7. OECD. Korea Economic Snapshot. Available online: http://www.oecd.org/economy/korea-economicsnapshot/ (accessed on 15 April 2020).

8. Lodato, T.; French, E.; Clark, J. Open government data in the smart city: Interoperability, urban knowledge, and linking legacy systems. J. Urban Aff. 2018. [CrossRef]

9. Lee, J.Y.; Anderson, C. The restored Cheonggyecheon and the quality of life in Seoul. The Impact of the Restored Cheongyecheon on Quality of Life in Seoul. J. Urban Technol. 2013, 20, 3-22. [CrossRef]

10. May, T.; Perry, B. Integrated Vision for Knowledge Cities; Centre for Sustainable Urban and Regional Futures, Salford University: Manchester, UK, 2011.

11. Sanchez, T.W.; Afzalan, N. Mapping the Knowledge Domain of Urban Planning. In Planning Knowledge and Research; Routledge: London, UK, 2017; pp. 69-84.

12. Pu, B.; Qiu, Y. A Bibliometric Analysis; On Urbanization Research From 1984 To 2013. Open House Int. 2015, 40, 37-43. 
13. Zhu, X.; Mu, X.; Hu, G. Ecological network analysis of urban energy metabolic system-A case study of Beijing. Ecol. Model. 2019, 404, 36-45. [CrossRef]

14. Badiu, D.L.; Nita, A.; Iojă, C.I.; Niţă, M.R. Disentangling the connections: A network analysis of approaches to urban green infrastructure. Urban For. Urban Green. 2019, 41, 211-220. [CrossRef]

15. Nagel, M.; Stark, M.; Satoh, K.; Schmitt, M.; Kaip, E. Diversity in collaboration: Networks in urban climate change governance. Urban Climate. 2019, 29, 100502. [CrossRef]

16. Filippini, R.; Mazzocchi, C.; Corsi, S. The contribution of Urban Food Policies toward food security in developing and developed countries: A network analysis approach. Sustain. Cities Soc. 2019, 47, 101506. [CrossRef]

17. Zhuang, T.; Qian, Q.K.; Visscher, H.J.; Elsinga, M.G.; Wu, W. The role of stakeholders and their participation network in decision-making of urban renewal in China: The case of Chongqing. Cities 2019, 92, 47-58. [CrossRef]

18. Im, T.; Lee, H.; Cho, W.; Campbell, J.W. Citizen Preference and Resource Allocation: The Case for Participatory Budgeting in Seoul. Local Gov. Stud. 2014, 40, 102-120. [CrossRef]

19. Campbell, J.W.; Cho, W. Two Faces of Government-Business Relations During South Korea's Developmental Period. Korean J. Comp. Gov. 2014, 18, 47-66.

20. National Assembly Budget Office. Available online: http://korea.nabo.go.kr/ (accessed on 20 February 2020).

21. Lee, J.Y. The Politics of Protest. Ph.D. Thesis, The City University of New York, New York, NY, USA, 1990.

22. Ha, S.K. Housing Crisis and Perspectives of Housing Policy in Korea. Hous. Stud. Rev. 1995, 3, $135-160$.

23. Cervero, R.; Kang, J.; Shively, K. From elevated freeways to surface boulevards: Neighborhood and housing price impacts in San Francisco. J. Urban. 2009, 2, 31-50. [CrossRef]

24. Replogle, M.; Kodransky, M. Urban Leaders Find Transportation Paths to Global Green Growth. Journeys Sharing Urban Transp. Solut. 2010, 4, 16.

25. Lee, J.Y.; Anderson, C. Cultural Policy and the State of Urban Development in the Capital of South Korea. In The Politics of Urban Cultural Policy: Global Perspectives; Grodach, C., Silver, D., Eds.; Routledge: London, UK, 2013; pp. 111-129.

26. Hwang, J.T. Territorialized urban mega-projects beyond global convergence: The case of Dongdaemun Design Plaza \& Park Project, Seoul. Cities 2014, 40, 82-89.

27. Kim, D.H.; Campbell, J.W. Development, Diversification, and Legitimacy: Emergence of the Committee-Based Administrative Model in South Korea. Public Org. Rev. 2014, 15, 551-564. [CrossRef]

28. Kang, C.D. Amenity-Oriented Public Investment and Land Market in Seoul. In The Changing Role of the Korean State: In the Post Developmental Era; Logos Verlag: Berlin, Germany, 2016; pp. 49-62.

29. Lee, Y.S.; Hwang, E.J. Global urban frontiers through policy transfer? Unpacking Seoul's creative city programmes. Urban Studi. 2012, 49, 2817-2837. [CrossRef]

30. Lee, J.Y.; Anderson, C. Urban Development. In Understanding Korean Public Administration: Lessons Learned from Practice; Park, K.K., Lee, W., Lee, S.H., Eds.; Routledge: London, UK, 2016; pp. 170-186.

31. Brownhill, S.; Darke, J. 'Rich Mix': Inclusive Strategies for Urban Regeneration; The Policy Press: Bristol, UK, 1998.

32. Anderson, C. Local Autonomy in South Korea. In Global Encyclopedia of Public Administration, Public Policy and Governance; Farazmand, A., Ed.; Springer: New York, NY, USA, 2018.

33. Borgatti, S.P.; Everett, M.G.; Freeman, L.C. Ucinet for Windows: Software for Social Network Analysis and Analytic Technologies; Harvard Press: Cambridge, MA, USA, 2002.

34. Zhang, H.; Fiszman, M.; Shin, D.; Miller, C.M.; Rosemblat, G.; Rindflesch, T.C. Degree centrality for semantic abstraction summarization of therapeutic studies. J. Biomed. Inf. 2011, 44, 830-838. [CrossRef] [PubMed]

35. Freeman, L.C. Centrality in Social Networks: I. Conceptual Classification. Soc. Netw. 1979, 1, $215-239$. [CrossRef]

36. Jung, K.; No, W.; Kim, J.W. Who leads nonprofit advocacy through social media: Some evidence from the Australian Marine Conservation Society's twitter networks. J. Contemp. East. Asia 2014, 13, 69-81. [CrossRef]

37. Jung, K.; Park, H.W. A semantic (TRIZ) network analysis of South Korea's "open public data" policy. Gov. Inf. Q. 2015, 32, 353-358. [CrossRef]

38. Lafosse, R.; Berge, J.M.F. A simultaneous CONCOR algorithm for the analysis of two partitioned matrices. Comput. Stat. Data Anal. 2006, 50, 2529-2535. [CrossRef]

39. Kwahk, K.Y. Social Network Analysis; Chenglam Press: Seoul, Korea, 2014. 
40. Park, S.D. The nexus of FDI, R\&D, and human capital on Chinese sustainable development: Evidence from a two-step approach. Sustainability 2018, 10, 2063.

41. Sung, B.; Park, S.-D. Who drives the transition to a renewable-energy economy? Multi-actor perspective on social innovation. Sustainability 2018, 10, 448. [CrossRef]

42. Kang, M.; Lee, C.S. Change and Comparison of Smart City Concept: A Case of Seoul. J. Korean Reg. Dev. Assoc. 2015, 27, 45-64.

43. Lee, K. Energy Politics and Civil Governance of Mayor Park Wonsoon in Metropolitan Seoul. Econ. Soc. 2015, 107, 140-172.

44. Anderson, C. A Comparative Analysis of Urban Redevelopment from the Viewpoint of Ethical Redevelopment: Seoul's Cheonggyecheon and the New York High Line. GRI Rev. 2019, 21, 99-124.

45. Townsend, A.M. Smart cities: Big data, civic hackers, and the quest for a new utopia, 1st ed.; WW Norton \& Company: New York, NY, USA, 2013.

46. Wang, H.J.; Anderson, C. History of Korean Urban Development. Global Encyclopedia of Public Administration, Public Policy and Governance; Farazmand, A., Ed.; Springer: New York, NY, USA, 2020.

47. Campbell, J.W. Public Procurement Policy in South Korea: Approaches to Sustainable Development and Anti-Corruption. In The Experience of Democracy and Bureaucracy in South Korea; Im, T., Ed.; Emerald Insight: Bingley, UK, 2017; pp. 159-179.

48. Gurran, N. Public Cities, Public Scholars? Questioning Urban Policy and Research in Australia. Urban Policy Res. 2018, 36, 1-10. [CrossRef]

49. Hasanagas Nikolaos, D. Managing information in forest policy networks: Distinguishing the influential actors from the "postmen". For. Policy Econ. 2016, 68, 73-80. [CrossRef]

(C) 2020 by the authors. Licensee MDPI, Basel, Switzerland. This article is an open access article distributed under the terms and conditions of the Creative Commons Attribution (CC BY) license (http://creativecommons.org/licenses/by/4.0/). 